\title{
Impact of thermal overload on the insulation aging in short duty cycle motors for aerospace
}

\author{
Vincenzo Madonna ${ }^{1}$, Paolo Giangrande ${ }^{1}$, Luca Lusuardi ${ }^{2}$, Andrea Cavallini ${ }^{2}$, Michael Galea ${ }^{1,3}$ \\ ${ }^{1}$ Power Electronics, Machines and Control Group, University of Nottingham, Nottingham, UK, exvm3@nottingham.ac.uk \\ ${ }^{2}$ Department of Electrical, Electronics and Information Engineering, University of Bologna, Bologna, Italy \\ ${ }^{3}$ School of Aerospace, University of Nottingham Ningbo, China
}

\begin{abstract}
Electric motors for aerospace applications are often characterised by short-time duty rather than continuous-duty operations. Some of the main requirements for these machines are high torque density and reliability. Considerable torque density improvement can be achieved by supplying the windings with current greater than the rated value and thus thermally overloading the machine for short periods of time. However, if the insulation is overheated, the machine lifetime is shortened, and reliability issues can arise. This paper experimentally investigates the influence of short-time thermal overload on the insulation lifetime of low voltage, random wound electrical machines. The analysis is performed on round enamelled magnet wires coils aged by accelerated thermal cycles, and the results are statistically processed by the two-parameter Weibull distribution. The experimental data is also used for building a lifetime estimation model, which is employed for predicting the lifetime of a motor embedded into an electromechanical actuator for landing gear extension/retraction.
\end{abstract}

Keywords-More Electric Aircraft, Electromechanical actuators, reliability, insulation, PMSM, Lifetime model.

\section{INTRODUCTION}

$\mathrm{T}$ HE last 15 years have seen a trend towards transportation electrification, especially in automotive and aerospace. In traditional aircraft, passengers comfort and safe operations are ensured by secondary power systems. These systems are generally driven by a combination of pneumatic, hydraulic, mechanical and electric power. With the more electric aircraft (MEA) initiative, there is an increasing trend to operate secondary systems through electric power [1,2]. A step towards aircraft electrification is represented by modern platforms such as the Boeing 787 and the Airbus A350-A380. In particular, the B787 features intensive electrification with a total electric power generation (main generators + auxiliary power units) of more than $1 M V A$ [3]. In this aircraft, services such as the environmental control system (ECS) and the wings anti icing are electrically driven. In traditional similarly sized aircraft (i.e. B767), these systems were powered by pneumatic bleed air, namely high pressure air extracted by the engines [3]. In the B787 the quasi-total removal of bleed air extraction from the engines allows for a fuel saving of almost $2 \%$ (with respect to

This work was funded by the INNOVATIVE doctoral programme. The INNOVATIVE programme is partially funded by the Marie Curie Initial Training Networks (ITN) action (project number 665468) and partially by the Institute for Aerospace Technology (IAT) at the University of Nottingham.

This work was also partially funded by the University of Nottingham Propulsion Futures Beacon. the B767) at cruise condition [3]. Another aspect of the MEA initiative is to replace hydraulically-operated actuators through electromechanical actuators (EMAs). Some proposed solutions include EMAs for primary and secondary flight control surfaces [4-6], landing gear extension/retraction and nose wheel steering systems [7]. One of the main advantages of using electrical machines (EMs) for operating EMAs is the flexibility that electric systems can offer [4, 8]. Hydraulically-operated actuators rely on more complex infrastructure than EMAs, which only require electric power. However, the main advantage of hydraulic actuators is the high force/torque density with respect to EMA. Improvements on EMA force/torque density can be achieved by taking action on EMs. The maximum achievable torque density of an EM is constrained by three factors, namely electromagnetic, mechanical and thermal limits [9]. The electromagnetic limit is related to the saturation of the electrical steel within the machine's stator and rotor cores. The mechanical limit is associated to the strength of mechanical components such as bearings and shaft. The thermal limit depends on the maximum temperature that insulating materials can withstand (i.e. thermal class). This last limitation can be overcome by an effective thermal management of EMs e.g. using forced liquid cooling $[10,11]$. Nevertheless, in order to avoid complex cooling methods, natural air cooled machines are generally preferred for EMA applications [12]. EMAs usually work with short-time duty, since the EM is operating for a brief period of time with respect to its thermal time constant (i.e. the time for reaching the $63.2 \%$ of the steady state temperature) [13]. For these EMs, excellent torque density can be achieved by feeding the windings with high current density. Traditional EMs are designed for a hot spot temperature always lower than the insulation thermal class. In fact, as per Montsinger/Arrhenius laws, every $8-10^{\circ} \mathrm{C}$ temperature increase halves the insulation lifetime [14-16]. In terms of insulation, the weakest component, is represented by the turn to turn enamel layer. Indeed, insulation-related failures are generally originated by a turn to turn breakdown. These insulation failures cause over-temperatures which can trigger most severe failure, such as phase to ground short-circuits, and eventually lead to the machine service outage.

This papers is thus focused on the analysis of the effects of short-time thermal overloads on the insulation aging of low voltage EMs. The analysis is experimentally carried out via accelerated lifetime tests performed on round enamelled 
magnet wire coils. The results are elaborated through the two-parameter Weibull distribution, and used for building a lifetime prediction model based on the Arrhenius law. The experimentally-tuned model is then employed for estimating the probability of failure of an EM integrated into a landing gear extension/retraction EMA.

\section{HELICOPTER LANDING GEAR ACTUATOR}

For investigating the effect of the short-time thermal overload on the insulation lifetime, a low voltage EM for aerospace applications is considered as a case-study. The selected machine drives a helicopter nose landing gear mechanism [17]. A schematic illustration of the landing gear retraction/extension mechanism is shown in Fig. 1. The system is actuated by a permanent magnet synchronous machine (PMSM) through a coupling gearbox and the PMSM is supplied through a power electronics converter (PEC) [18]. In Fig. 2, the PMSM is shown and its main characteristics are reported in TABLE I, alongside with the main parameters of the PEC [19]. The landing gear EMA is only operated after taking off and before landing. Therefore, it is activated for a short period of time compared to the total flight length. The time necessary for a single extension / retraction cycle is equal to $20 \mathrm{~s}$. However, for safety reasons, the actuator should be able to perform three cycles in a row without any cooling-down time, according to the mission profile reported in Fig. 3.

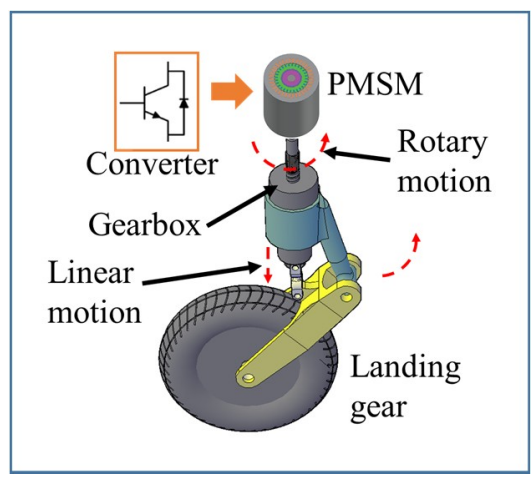

Fig. 1. Diagram of the helicopter landing gear EMA.

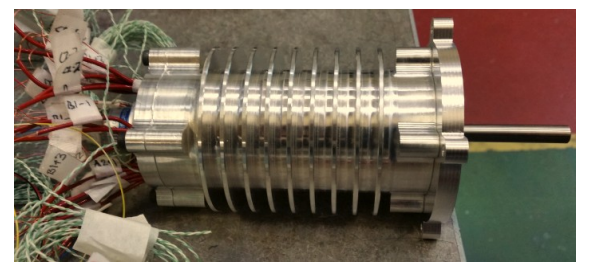

Fig. 2. PMSM driving the landing gear EMA.

TABLE I List of Drive PARAmeters

\begin{tabular}{cc}
\hline \hline Parameter & Data \\
\hline Slot number (Q) & 12 \\
Pole number (2p) & 10 \\
Turns per coil (nt) & 100 \\
Number of strands (ns) & 1 \\
Single conductor diameter $\left(\mathbf{D}_{\mathbf{c}}\right)$ & $0.511 \mathrm{~mm}$ \\
Copper fill factor (ff) & $50 \%$ \\
Winding configuration & Concentrated \\
Insulation Thermal Class & $200{ }^{\circ} \mathrm{C}$ \\
Max DC link voltage & $270 \mathrm{~V}$ \\
Max fundamental frequency & $208 \mathrm{~Hz}$ \\
Max switching frequency & $10 \mathrm{kHz}$ \\
Distance PEC-PMSM & $<0.5 \mathrm{~m}$ \\
\hline \hline
\end{tabular}

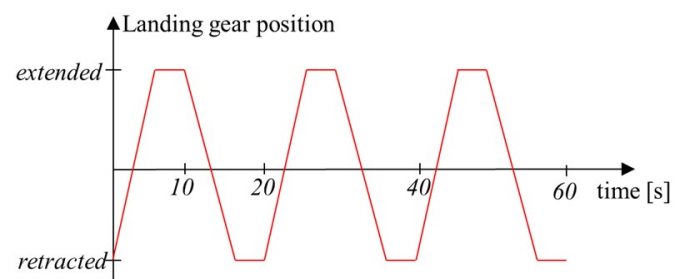

Fig. 3. EMA mission profile.

The PMSM was tested at the rated operating condition (i.e. rated current) in order to identify the hot spot temperature and to fine-tune its lumped parameter thermal network (LPTN), originally developed in [19]. The measured hot spot temperature, alongside with the LPTN predicted temperature are provided in Fig. 4. In the following sections, the implemented fine-tuned LPTN is used for evaluating the PMSM's temperature profile in overload conditions.

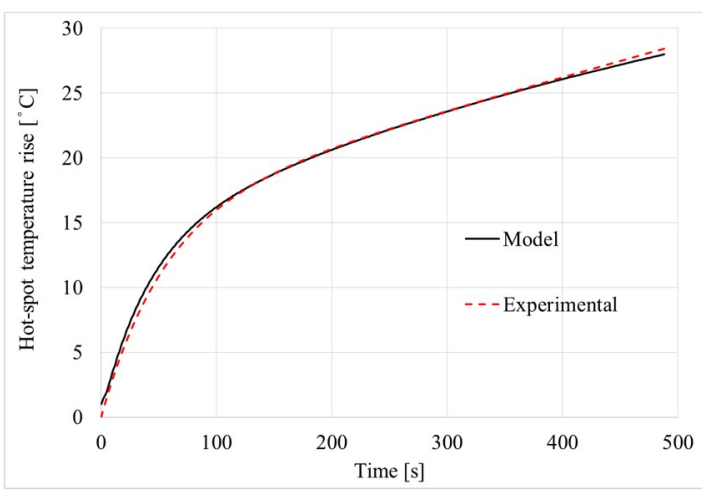

Fig. 4. Hot spot temperature rise at rated current: measured (black solid line) and LPTN predicted (red dashed line).

\section{THERMAL CYCLES EXPERIMENTS}

Accelerated aging tests are widely adopted for estimating the service life of EMs [20]. During these tests, the insulation is exposed to a stress above the level expected during normal operations. The test outcome is post-processed, and the life at "normal" stress level is then extrapolated through lifetime models.

For thermal aging, the Arrhenius model, proposed for the first time by Dakin in 1947 [15], is commonly used. Based on Arrhenius law, the lifetime $L$ (in unit measure of time) of a solid insulating material, when operating at temperature $\theta$, can be calculated by (1), where $A$ and $B$ are parameters depending on the material [21].

$$
L=A \cdot \exp (B / \theta)
$$

If the thermal class of the insulation $\theta_{0}$ is known, then (1) can be rearranged as in (2) [16]. Where $L_{0}$ is the life at temperature $\theta_{0}$ and it is generally equal to 20,000 hours for enamelled wires.

$$
L=L_{0} \cdot \exp \left[B\left(\frac{1}{\theta}-\frac{1}{\theta_{0}}\right)\right]
$$

From (1) and (2), the Montsinger rule can be derived as expressed by (3), where HIC is the halving interval, which identifies the temperature increase in Celsius degrees for a corresponding $50 \%$ lifetime reduction $[14,22,23]$.

$$
L=L_{0} \cdot 2^{\frac{\theta_{0}-\theta}{H I C}}
$$




\section{A. Specimens characteristics}

The tested specimens are coils made of a class 200 round magnet wire with double enamel layer (i.e. a modified polyester base coat and a polyamide-imide over coat). The main properties of the specimens are reported in TABLE II. The coils are hung on a PTFE rod and inserted into a fume hood with variable air flow-rate, as shown in Fig. 5. Regulating the flowrate, it is possible to adjust the convection heat exchange between coils and air. Thus, the coils' cool-down period is varied.

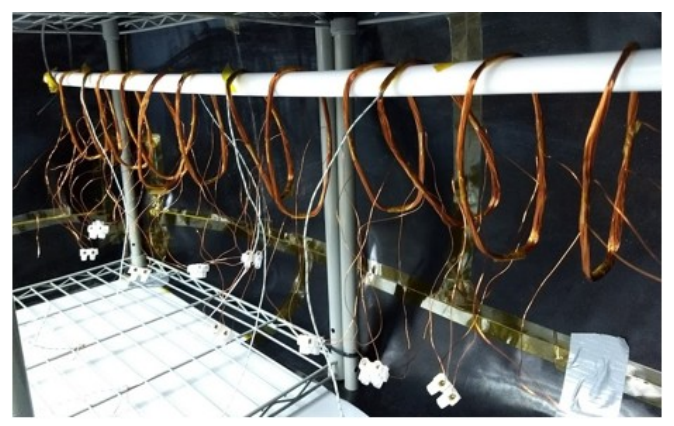

Fig. 5. Coils hung to a PTFE rod inside the fume hood.

Generally, thermal tests are performed using formettes resembling a portion of the actual EM's stator core. By adopting the formette, the thermal inertia of the samples (i.e. coil + motorette) is significantly increased. Hence, the rise and fall times of the temperature profile are considerably affected leading to 1) minor temperature variations for short-time duty cycles or 2) longer experiments duration for the same temperature range. Considering that the application under study is characterised by short-time duty cycle and the presented analysis aims to investigate a wide range of temperature (i.e. large temperature variations), the experiments are carried out on specimens (i.e. coils). The schematic of the test setup is depicted in Fig. 6. The specimens are heated exploiting the Joule effect, thus they are fed using a DC power supply. The coils temperatures are measured by means of K-type thermocouples uniformly distributed within the specimens. The measured temperatures are elaborated by a digital signal processor (DSP) which also controls the DC power supply via the analog interface. The applied temperature profile is shaped by selecting the suitable DC current value and the proper air flow-rate of the fume hood.

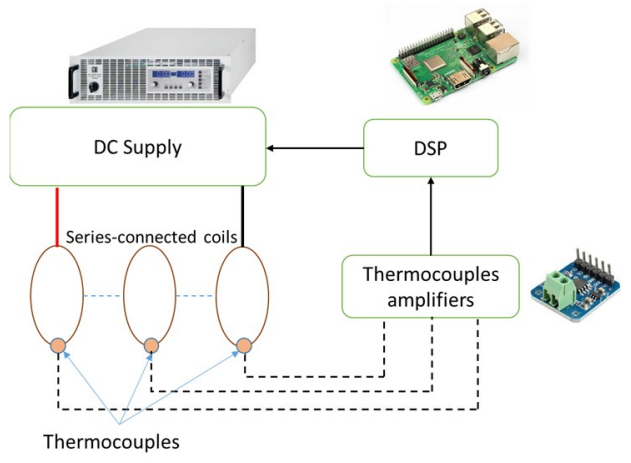

Fig. 6. Schematic description of the test set-up.
TABLE II SPECIMENS PARAMETERS

\begin{tabular}{cc}
\hline Parameter & Dimensions \\
\hline Thermal class & 200 \\
Number of turns & 20 \\
Strands in parallel & 2 \\
Copper core diameter & $0.4 \mathrm{~mm}$ \\
Average turn length & $250 \mathrm{~mm}$ \\
\hline \hline
\end{tabular}

The accuracy and the statistical validity of accelerated aging tests are largely reliant on the number of tested specimens. No recommendations are provided by standards regarding tests at variable temperature for low voltage coils. However, for tests at constant temperature, the standards generally recommend to use at least 10 specimens for each temperature [24]. In this case, 14 specimens are aged for each temperature profile.

\section{B. Temperature profiles definition}

Before performing the experiments, the temperature profiles are defined, according to the following constraints: 1) the duty cycles should have the same order of magnitude as the analysed application and 2) the temperatures should be higher than the magnet wire thermal class. Two temperature profiles are determined, as reported in Fig. 7. They are named hereafter as TP-long (Fig. 7.a) and TP-short (Fig. 7.b). Both profiles are characterised by the same maximum and minimum temperatures, but they have different time periods $\Delta t$ (i.e. $\Delta t_{\text {long }}=260 \mathrm{~s}$ and $\Delta t_{\text {short }}=77 \mathrm{~s}$ ). Identical peak to peak temperatures are adopted for verifying the influence of the profile period on the specimens' lifetime.

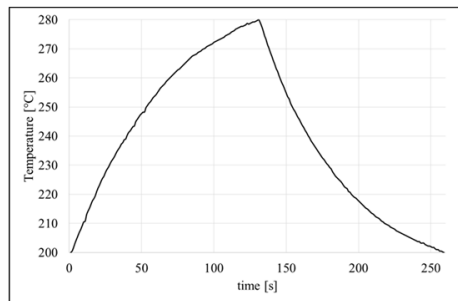

(a)

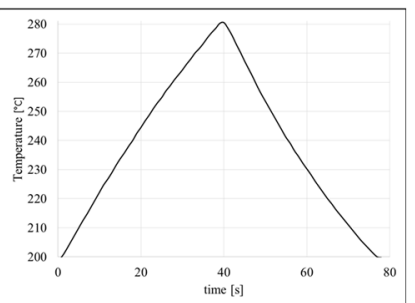

(b)
Fig. 7. Selected temperature profiles: a) TP-long and b)TP-short.

\section{End of life criterion}

The specimens are aged by exposure cycles of $24 h$. At the end of every exposure cycle, the insulation condition of each single specimen is assessed through the DC dielectric withstand test (also called DC Hipot test). This pass/fail test consists in applying $1 \mathrm{kV} \mathrm{DC}$ voltage for one minute. Since the single coil is formed by two parallel sub-coils (i.e. two strands), the DC voltage is applied between the strands for testing the strand to strand insulation. If the specimen fails the DC Hipot test (i.e. the insulation does not resist the $1 \mathrm{kV}$ DC voltage and the end of life occurs), it is removed from the experiment. The sample time to failure is calculated as the sum of the total thermal exposure hours minus the duration of half cycle (i.e. the end of life is assumed to be occurred at half of the last thermal cycle) [24]. The time to failure value thus obtained is recorded. Fig. 8 shows a coil after 10 aging cycles, together with an unaged coil. 


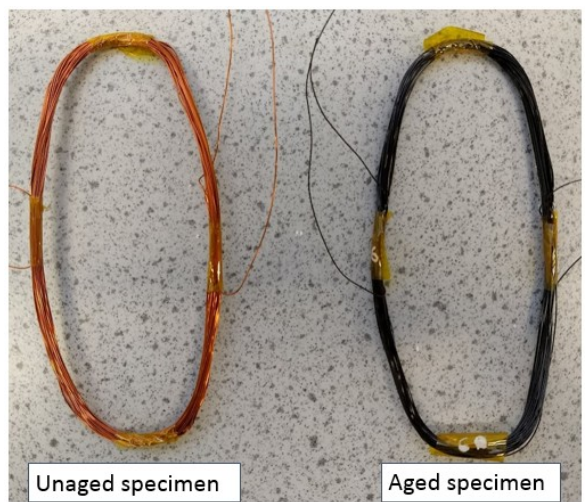

Fig. 8. Comparison between unaged (left) and thermally aged (right) specimens.

Looking at the aged coil (right-hand side of Fig. 8), it is possible to observe the colour change of the enamel coating caused by the overheating. In addition, some of the specimens were submitted to a visual screening using an optical microscope, prior and after the thermal cycles. In certain cases, cracks in the enamel coating were noted at the end of cycle, as proven by the enlargement in Fig. 9.

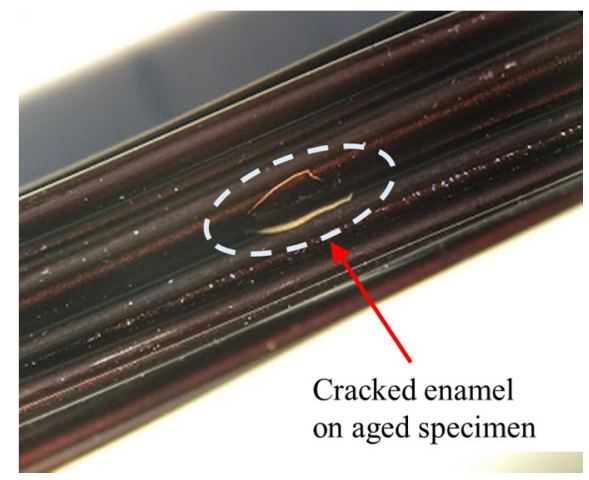

Fig. 9. Optical microscope analysis of thermally-aged specimen.

\section{RESULTS POST-PROCESSING AND DISCUSSION}

\section{A. Weibull distribution}

The two-parameter Weibull distribution has been used for post-processing the time to failures experimental data. The Weibull cumulative distribution function can be described as in (4), where $t$ is the time to failure, $\alpha$ is the scale parameter and $\beta$ is the shape parameter.

$$
F(t)=1-\exp \left[-\left(\frac{t}{\alpha}\right)^{\beta}\right]
$$

In particular, $\alpha$ is the $63.2 \%$ percentile of time to failure, while $\beta$ represents the inverse of the data scatter, which is proportional to the variance of the time to failures [25]. The Weibull probability plot with $95 \%$ confidence intervals (CI) for TP-long and TP-short are presented in Fig. 10. The probability plot for TP-long shows a good fit with the Weibull distribution. Nonetheless, the probability plot for TP-short reveals a number of different failure modes which will be subject of further investigation.

\section{B. Discussion}

The mean time to failure (MTTF) for both temperature profiles along with the $95 \% \mathrm{CI}$ are reported in TABLE III. It can be noted that the CI of the two MTTF overlaps. However, it is trivial to demonstrate that the two statistical distribution are significantly different $[26,27]$.

TABLE III MTTF FOR THE ANALYSED TEMPERATURE PROFILES

\begin{tabular}{ccccc}
\hline \hline Temp. Profile & (lower CI) & MTTF & (upper CI) & Std error \\
\hline TP-long & $278 \mathrm{~h}$ & $306 \mathrm{~h}$ & $336 \mathrm{~h}$ & $15 \mathrm{~h}$ \\
TP-short & $325 \mathrm{~h}$ & $368 \mathrm{~h}$ & $416 \mathrm{~h}$ & $23 \mathrm{~h}$ \\
\hline \hline
\end{tabular}

The lifetime model based on the Arrhenius equation has been implemented in Matlab environment adopting the approach proposed in [28]. The specimens life, $L$, can be divided into $K$ equal intervals of same duration $\Delta t$ (i.e. the temperature profile's period). Thus, $L$ can be expressed as in (5).

$$
L=K \Delta t
$$

Each time interval $\Delta t$ can be split into infinitesimal intervals ranging from a generic time $t$ to a successive time $t+d t$, and in each infinitesimal interval the temperature can be considered constant. The "loss-of-life" fraction in the infinitesimal interval $d t$ can be calculated as in (6) [28].

$$
d L F[\theta(t)]=\frac{d t}{L_{0} \cdot \exp \left[B\left(\frac{1}{\theta(t)}-\frac{1}{\theta_{0}}\right)\right]}
$$

The loss-of-life fraction relative to the generic temperature profile $\theta j(t)$, having period $\Delta t_{j}$ can be derived as

$$
L F\left[\theta_{j}(t)\right]=\int_{0}^{\Delta t_{j}} \frac{d t}{L_{0} \exp \left[B\left(\frac{1}{\theta j(t)}-\frac{1}{\theta_{0}}\right)\right]}
$$

According to the cumulative damage law [29], when the insulation reach the end of life, the sum of all the loss-of-life fractions must be equal to 1 as reported in (8).

$$
\int_{0}^{L} d L F\left[\theta_{j}(t)\right]=K \cdot L F\left[\theta_{j}(t)\right]=1
$$

Thus, the number of cycles to failure, $K$, can be calculated as

$$
K=1 / L F\left[\theta_{j}(t)\right]
$$

A system of 2 equations can be defined as shown in (10), where $K_{\text {short }}$ and $K_{\text {long }}$ are the number of cycles to failure for the temperature profile TP-short and TP-long respectively, whilst $\theta_{\text {short }}(t)$ and $\theta_{\text {long }}(t)$ are the temperature functions (i.e. temperature vs. time) corresponding to TP-short and TP-long (in Kelvin degrees) respectively. For the sake of clarity, $K_{\text {short }}$ and $K_{\text {long }}$ can be computed trivially by calculating the ratio between the median of time to failure (at the lower confidence bound) and the corresponding period (i.e. $\Delta t_{\text {short }}$ and $\Delta t_{\text {long }}$ ).

$$
\left\{\begin{array}{c}
K_{\text {short }} \int_{0}^{\Delta t_{\text {short }}} \frac{d t}{L_{0} \exp \left[-B\left(\theta_{0}^{-1}-\theta_{\text {short }}(t)^{-1}\right)\right]}=1 \\
K_{\text {long }} \int_{0}^{\Delta t_{\text {long }}} \frac{d t}{L_{0} \exp \left[-B\left(\theta_{0}^{-1}-\theta_{\text {long }}(t)^{-1}\right)\right]}=1
\end{array}\right.
$$

The previously reported system of equations has been solved numerically in order to evaluate $B$ and $L_{0}$. For the examined insulation, $B$ is equal to 19,787 and $L_{0}$ (corresponding to a temperature $\theta_{0}=273.15+200 \mathrm{~K}$ ) is 27,290 hours. The obtained value of $L_{0}$ is in accordance with the declared thermal class of the employed magnet wire (i.e. class 200).

\section{LIFETIME MODEL - STUDY CASE APPLICATION}

The implemented lifetime model is employed for predicting the lifetime consumption of the coil insulation, when thermally-overloaded. The investigation is performed considering the PMSM presented in Section II and integrated into the landing gear EMA. 

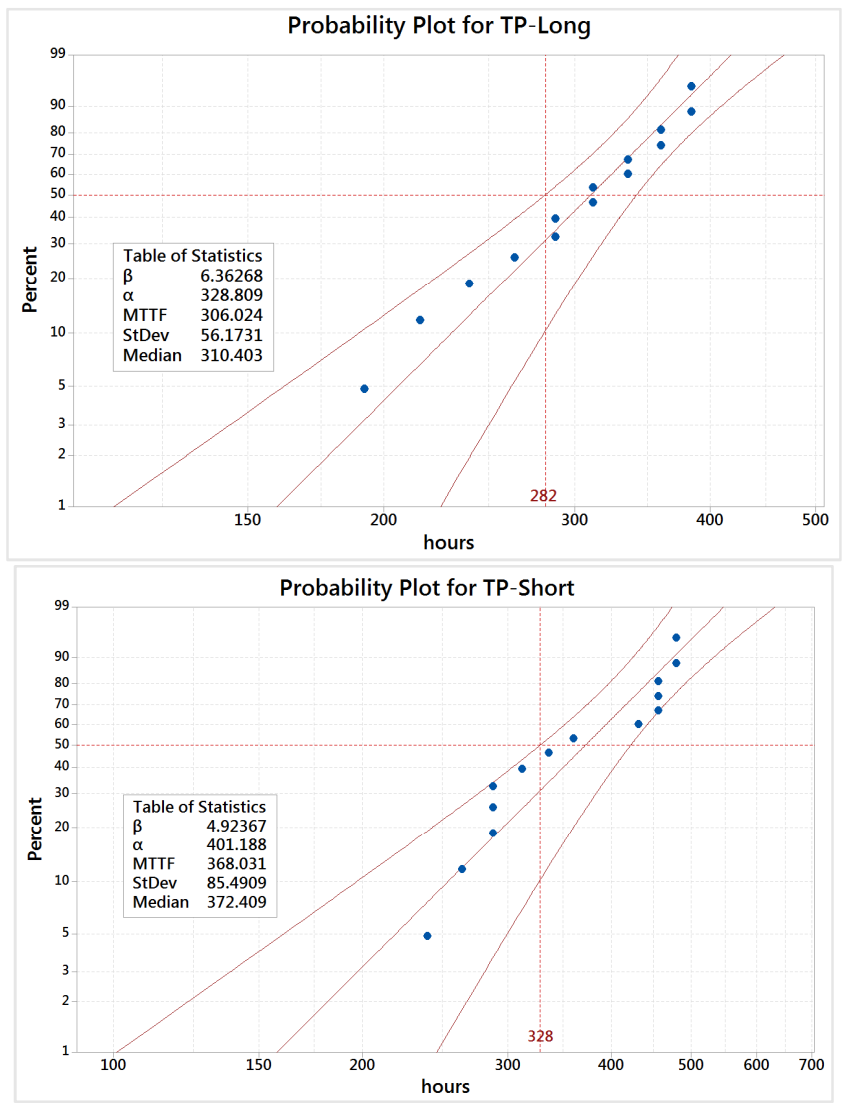

Fig. 10 Weibull probability plot for TP-Long (top sub-plot) and TP Short (bottom sub-plot).

The fine-tuned LPTN (see Fig. 4) is used for determining the hot spot temperature profile of the PMSM, in case of thermal overload. For this purpose, three consecutive EMA extension/retraction cycles are performed (i.e. $60 s$ total operating time, as in Fig. 3), along with a current 4 times higher than the rated one. The LPTN estimated temperature profile (in thermal overload condition) is depicted in Fig. 11. Some considerations regarding Fig. 11 can be made:

1. The starting temperature is set to $70{ }^{\circ} \mathrm{C}$ (i.e. worst-case scenario for aerospace applications);

2. Temperatures below the insulation thermal class (i.e. $200{ }^{\circ} \mathrm{C}$ ) are assumed to give a minor contribution to the thermal aging and thus they are neglected in the following analysis.

According to the above considerations, the input temperature profile of the lifetime model is the one highlighted with the red dashed box in Fig. 11 (portion above $200{ }^{\circ} \mathrm{C}$, from $28 s$ to $82 s$ ) and defined as TP-EMA.

As outcome of the lifetime model simulation, the number of cycles to failure for the temperature profile TP-EMA, $K_{E M A}$, is equal to 25,611 .

Assuming that two EMA cycles are performed for every flight (take-off and landing) with each lasting 1 minute (i.e. worst case scenario), then 12,805 flights are ensured before a $50 \%$ probability of turn to turn insulation failure (due to thermal aging) is reached. It is important to underline that the proposed lifetime model is built considering the median of the lifetime. Nonetheless, different percentiles of the Weibull distribution can be adopted.

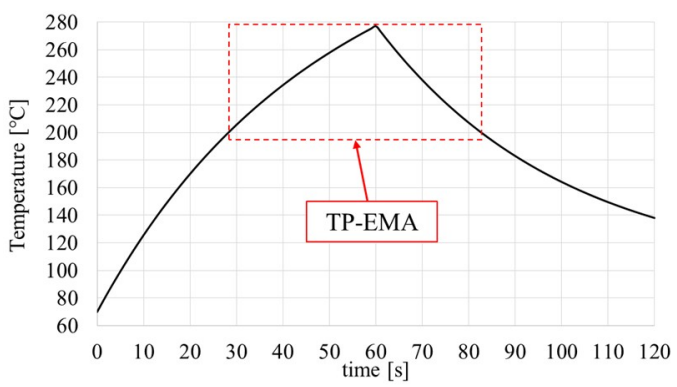

Fig. 11. Temperature profile of the EMA during a single mission when thermally overloaded.

It is also important to remark that turn to turn insulation failure does not imply an out of service EMA. EMs for safety critical applications are usually designed with multiple level of redundancy in order to operate even during severe fault conditions.

\section{CONSIDERATIONS ON THE PRESENTED ANALYSIS}

For all the analysis carried out in the previous sections, it has been assumed that the thermal stress is the only factor contributing to the aging of the insulation. However, several other factors contribute in shortening its lifetime. The most relevant aging factors, alongside with thermal, are the electrical, mechanical and environmental stresses.

For low voltage EMs, electrical aging is generally neglected since the voltage across the insulation is below the partial discharge inception voltage (PDIV). However, for EMs fed by PWM converters, several studies have proven that partial discharges (PDs) can be incepted even in low voltage EMs [30, 31]. PDs inception is caused by fast switching devices (e.g. SiC power modules) with elevated $\mathrm{dV} / \mathrm{dt}$ waveforms and multiple waveform reflections, which can amplify the voltage across the turn's insulation. Additionally, based on Paschen's law, the voltage necessary to incept a discharge between two electrodes at fixed distance, decreases at low pressure. This later aspect is crucial for electrical devices adopted in aerospace applications, since high altitude corresponds to lower ambient pressure with respect to sea level. Consequently, the voltage level should be carefully chosen for avoiding the inception of PDs which can cause the premature insulation breakdown. If higher DC link voltage and faster switching devices are employed, the proposed end of life criterion might be inappropriate. In fact, standards recommend to test the insulation through voltage impulses, and to use the repetitive partial discharge inception as end of life criterion $[32,33]$. Mechanical vibrations represent another aging factor, which generally occur in transportation applications [25]. The experimental study presented here, revealed that the insulation coating becomes brittle after few days of thermal cycling above its thermal class. Hence, mechanical vibrations and/or shocks might lead to the enamel detachment. Silicone-based varnishes could be used for minimising or preventing the enamel detachment.

\section{CONCLUSIONS}

The paper presented an experimental investigation on the thermal aging of low voltage random wound coils. The study was performed considering a short-duty PMSM for helicopter landing gear EMA. The proposed analysis was aimed to assess and quantify the influence of thermal overload on the insulation 
lifetime. The specimens (i.e. random wound coils) were tested using two temperature profiles characterised by the same temperature range (all above the insulation thermal class), but different rise and fall times. The DC Hipot test was used as end-life criterion of the specimens. The collected experimental data were statically post-processed for developing a lifetime model based on Arrhenius law. The lifetime model was employed for predicting the remaining life after a continuous thermal overload exposure. It was found that, despite the considerable thermal overload (i.e. 4 times the rated current), the PMSM can withstand 25,611 activations before the failure probability rises up to $50 \%$. For the considered aerospace EMA application, this correspond to a number of flights higher than 12,000. The authors would like to remark that the choice of considering the extension/retraction landing gear EMA as study case was motivated by the availability of the EM. However, the outcomes of the presented analysis have general validity and they can be extended to different short duty EMs adopting the investigated insulation. Future work will investigate the combined effect of thermal, electrical and environmental stresses on the insulation lifetime with the purpose of producing a comprehensive aging model.

\section{REFERENCES}

[1] B. Sarlioglu and C. T. Morris, "More Electric Aircraft: Review, Challenges, and Opportunities for Commercial Transport Aircraft," IEEE Transactions on Transportation Electrification, vol. 1, pp. 54-64, 2015.

[2] R. Glassock, M. Galea, W. Williams, and T. Glesk, "Hybrid Electric Aircraft Propulsion Case Study for Skydiving Mission," Aerospace. 2017; 4(3):45, 2017.

[3] V. Madonna, P. Giangrande, and M. Galea, "Electrical Power Generation in Aircraft: review, challenges and opportunities.," in press on IEEE Transactions on Transportation Electrification, DOI: 10.1109/TTE.2018.2834142, 2018.

[4] A. Boglietti, A. Cavagnino, A. Tenconi, S. Vaschetto, "The safety critical electric machines and drives in the more electric aircraft: A survey," in 2009 35th Annual Conference of IEEE Industrial Electronics, 2009, pp. 2587-2594.

[5] W. Cao, B. C. Mecrow, G. J. Atkinson, J. W. Bennett, and D. J. Atkinson, "Overview of Electric Motor Technologies Used for More Electric Aircraft (MEA)," IEEE Transactions on Industrial Electronics, vol. 59, pp. 3523-3531, 2012.

[6] C. I. Hill, S. Bozhko, Y. Tao, P. Giangrande, and C. Gerada, "More Electric Aircraft Electro-Mechanical Actuator Regenerated Power Management," in 2015 IEEE 24th International Symposium on Industrial Electronics (ISIE), 2015, pp. 337-342.

[7] J. W. Bennett, "Fault tolerant electromechanical actuators for aircraft," PhD Thesis, Newcastle University, 2010.

[8] P. Giangrande, C. I. Hill, S. V. Bozhko, and C. Gerada, "A novel multilevel electro-mechanical actuator virtual testing and analysis tool," in 7 th IET International Conference on Power Electronics, Machines and Drives (PEMD 2014), 2014, pp. 1-6.

[9] M. Galea, C. Gerada, T. Raminosoa, and P. Wheeler, "A Thermal Improvement Technique for the Phase Windings of Electrical Machines," IEEE Transactions on Industry Applications, vol. 48, pp. 7987, 2012.

[10] Z. Xu, A. Al-Timimy, M. Degano, P. Giangrande, G. L. Calzo, H. Zhang, et al., "Thermal management of a permanent magnet motor for an directly coupled pump," in 2016 XXII International Conference on Electrical Machines (ICEM), 2016, pp. 2738-2744.

[11] Z. Xu, C. Tighe, M. Galea, T. Hamiti, C. Gerada, and S. J. Pickering, "Thermal design of a permanent magnetic motor for direct drive wheel actuator," in 2014 International Conference on Electrical Machines (ICEM), 2014, pp. 2186-2192.
[12] C. Gerada, M. Galea, and A. Kladas, "Electrical machines for aerospace applications," in 2015 IEEE Workshop on Electrical Machines Design, Control and Diagnosis (WEMDCD), 2015, pp. 79-84.

[13] C. Sciascera, M. Galea, P. Giangrande, and C. Gerada, "Lifetime consumption and degradation analysis of the winding insulation of electrical machines," in 8th IET International Conference on Power Electronics, Machines and Drives (PEMD 2016), 2016, pp. 1-5.

[14] V. M. Montsinger, "Loading Transformers By Temperature," Transactions of the American Institute of Electrical Engineers, vol. 49, pp. 776-790, 1930

[15] T. W. Dakin, "Electrical Insulation Deterioration Treated as a Chemical Rate Phenomenon," Transactions of the American Institute of Electrical Engineers, vol. 67, pp. 113-122, 1948.

[16] G. C. Montanari and L. Simoni, "Aging phenomenology and modeling," IEEE Transactions on Electrical Insulation, vol. 28, pp. 755-776, 1993.

[17] C. Sciascera, P. Giangrande, C. Brunson, M. Galea, and C. Gerada, "Optimal design of an electro-mechanical actuator for aerospace application," in IECON 2015 - 41st Annual Conference of the IEEE Industrial Electronics Society, 2015, pp. 001903-001908.

[18] A. Al-Timimy, M. Degano, P. Giangrande, G. L. Calzo, Z. X. M. Galea, C. Gerada, et al., "Design and optimization of a high power density machine for flooded industrial pump," in 2016 XXII International Conference on Electrical Machines (ICEM), 2016, pp. 1480-1486.

[19] C. Sciascera, P. Giangrande, L. Papini, C. Gerada, and M. Galea, "Analytical Thermal Model for Fast Stator Winding Temperature Prediction," IEEE Transactions on Industrial Electronics, vol. 64, pp. 6116-6126, 2017.

[20] G. C. Stone, I. Culbert, E. A. Boulter, and H. Dhirani, Electrical Insulation for Rotating Machines: Design, Evaluation, Aging, Testing, and Repair: Wiley, 2014.

[21] L. Simoni, "A General Approach to the Endurance of Electrical Insulation under Temperature and Voltage," IEEE Transactions on Electrical Insulation, vol. EI-16, pp. 277-289, 1981.

[22] E. L. Brancato, "Estimation of lifetime expectancies of motors," IEEE Electrical Insulation Magazine, vol. 8, pp. 5-13, 1992.

[23] R. Rothe and K. Hameyer, "Life expectancy calculation for electric vehicle traction motors regarding dynamic temperature and driving cycles," in 2011 IEEE International Electric Machines \& Drives Conference (IEMDC), 2011, pp. 1306-1309.

[24] "ASTM D2307-07a (2013): Standard Test Method for Thermal Endurance of Film-Insulated Round Magnet Wire," ed. ASTM International, West Conshohocken, PA, 2013, https://doi.org/10.1520/D2307-07AR13, 2013.

[25] P. Mancinelli, S. Stagnitta, and A. Cavallini, "Qualification of Hairpin Motors Insulation for Automotive Applications," IEEE Transactions on Industry Applications, vol. 53, pp. 3110-3118, 2017.

[26] A. Knezevic, "Overlapping confidence intervals and statistical significance,"Available: https://www.cscu.cornell.edu/news/statnews/st news73.pdf, 2008.

[27] P. C. Austin and J. E. Hux, "A brief note on overlapping confidence intervals," Journal of Vascular Surgery, vol. 36, pp. 194-195, 2002/07/01/2002.

[28] G. Mazzanti, "Analysis of the Combined Effects of Load Cycling, Thermal Transients, and Electrothermal Stress on Life Expectancy of High-Voltage AC Cables," IEEE Transactions on Power Delivery, vol. 22, pp. 2000-2009, 2007.

[29] M. A. Miner, "Cumulative Damage in Fatigue," Journal of Applied Mechanics, pp. A159-A163, 1945.

[30] M. Tozzi, A. Cavallini, and G. C. Montanari, "Monitoring off-line and on-line PD under impulsive voltage on induction motors - part 1: standard procedure," IEEE Electrical Insulation Magazine, vol. 26, pp. 16-26, 2010.

[31] M. Tozzi, A. Cavallini, and G. C. Montanari, "Monitoring off-line and on-line PD under impulsive voltage on induction motors - Part 2: testing*," IEEE Electrical Insulation Magazine, vol. 27, pp. 14-21, 2011.

[32] L. Lusuardi, A. Cavallini, and M. Degano, "The impact of impulsive voltage waveforms on the electrical insulation of actuators for more electrical aircraft (MEA)," in IECON 2017 - 43rd Annual Conference of the IEEE Industrial Electronics Society, 2017, pp. 4414-4418.

[33] "IEC 60034-18-41:2014 Rotating electrical machines - Part 18-41: Partial discharge free electrical insulation systems (Type I) used in rotating electrical machines fed from voltage converters - Qualification and quality control tests ", ed: IEC, 2014. 